\title{
HUBUNGAN MUTU PELAYANAN DENGAN KEPUASAN PASIEN DI RUANG RAWAT INAP RUMAH SAKIT TENTARA PEKANBARU
}

\author{
Jihan Natassa dan Afrizah \\ STIKes Hang Tuah Pekanbaru \\ Email: jihan natassa@yahoo.co.id
}

\begin{abstract}
Satisfaction beginning of the acceptance of the patient first came to the patient leaves the hospital (Herlambang, 2016). Four-level military hospital pekanbaru 01.07.04 has a fundamental duty to implement health care outpatient and inpatient, where the value BOR 25,08 \%, Initial surveys are known to many complain to the patients so that they are less satisfied. Intention of this research is what is there is relationship quality of care and patient's satisfactioninpatient unit four level military hospital Pekanbaru 2016. This Research method is analytic quantitative with research desain use transversal crosscut approach (sectional cross) its responder is patients inpatient in the mounth of May until June 2016.This Research Sample counted 87 people patients inpatient. Technique intake of sample isnon probability sampling. Analysis the used is analysis of univariat bivariate and with test of Chi-Square, measure instrument the used is data processing and questionnaires use computerization. Result of research show there are relation between reability (Value $P$ 0,003, value of $O R=4,313$ ), assurance (Value $P$ 0,034, value of OR=2,833), tangibles (Value $P \quad 0,006$, value of $O R=3,882$ ), emphaty (Value $P 0,022$, value of OR=3,257), responsiveness (Value $P 0,003$,value of $O R=4,308$ ) with patient satisfaction in the inpatient unit four level military hospital Pekanbaru 2016. Suggested to the relevan agencies, namely the military hospital to improve the quality of services provided to inpatient through training to health workers.
\end{abstract}

Keywords: Patient satisfaction, Quality of care, Pekanbaru

\section{PENDAHULUAN}

Kepuasan merupakan konsep yang terkait erat dengan jenis perilaku pada tahap pasca pembelian/konsumsi. Rasa puas atau tidak puas terhadap konsumsi suatu produk adalah hasil evaluasi alternatif pasca konsumsi atau evaluasi alternatif tahap kedua (Setyobudi, 2014).

Kepuasan pasien tergantung pada kualitas pelayanan. Pelayanan adalah semua upaya yang dilakukan karyawan untuk memenuhi keinginan pelanggannya dengan jasa yang akan diberikan. Suatu pelayanan dikatakan baik oleh pasien, ditentukan oleh kenyataan apakah jasa yang diberikan bisa memenuhi kebutuhan pasien, dengan menggunakan persepsi tentang pelayanan yang diterima (memuaskan atau mengecewakan, juga termasuk lamanya waktu pelayanan). Kepuasan dimulai dari penerimaan terhadap pasien dari pertama kali datang, sampai pasien meninggalkan rumah sakit.

Mutu pelayanan kesehatan menjadi hal yang sangat penting dalam organisasi pelayanan kesehatan, peningkatan kesadaran masyarakat tentang kesehatan dan pelayanan kesehatan mendorong setiap organisasi pelayanan kesehatan untuk sadar mutu dalam memberikan pelayanan kepada pengguna jasa organisasi pelayanan kesehatan. Setiap permasalahan yang muncul dalam organisasi pelayanan kesehatan khususnya berkaitan dengan mutu layanan kesehatan, terdapat tiga konsep utama yang selalu muncul. Konsep tersebut adalah akses, biaya dan mutu. Tentu saja akses mencakup akses fisik, keuangan, mental atau intelektual sumber daya manusia terhadap perawatan dan layanan kesehatan yang tersedia. Dari ketiga konsep tersebut, elemen kepuasan konsumen merupakan hal terpenting. Jika konsumen tidak puas dengan mutu layanan yang diberikan, pasien tidak akan kembali atau mencari layanan lainnya, walaupun layanan tersebut tersedia, mudah didapat dan mudah dijangkau (Herlambang, 2016).

Survei awal yang peneliti lakukan di Rumah Sakit Tentara Tk IV 01.07.04 Pekanbaru, melalui observasi dilapangan terlihat perawat kurang peduli terhadap pasien apabila pasien menyampaikan keluhan, petugas kurang komunikatif dengan pasien, perawat terlihat kurang ramah terhadap pasien, kurang disiplin pada saat jam kerja, dan hasil wawancara 
terhadap 10 responden di ruang rawat inap didapatkan informasi 7 orang pasien mengatakan kurang mendapat pelayanan yang baik dikarenakan sikap petugas yang tidak ramah terhadap pasien dan juga empati petugas kurang baik,tidak tersedianya tempat duduk bagi pengunjung di ruangan serta tidak adanya pembatas antar pasien di ruangan, tempat parkir yang disediakan terlalu sempit sehingga menyebabkan pasien kurang puas.

Tujuan dari penelitian ini adalah diketahuinya hubungan mutu pelayanan dengan kepuasan pasien di Ruang Rawat Inap Rumah Sakit Tentara Tk IV 01.07.04 Pekanbaru Tahun 2016.

\section{METODOLOGI PENELITIAN}

Jenis penelitian yang digunakan adalah penelitian kuantitatif, dengan menggunakan desain cross-sectional dimana data yang menyakut variabel jamainan, Empati, bukti fisik) dan variabel terikat (kepuasan pasien), akan dikumpulkan dalam waktu yang bersamaan. Penelitian ini dilakukan di Rumah Sakit Tentara Tk IV 01.07.04 Pekanbaru pada bulan Mei sampai Juni 2016. Besar sampel dalam penelitian ini yaitu 87 responden. Jenis data yang dikumpulkan adalah data primer yaitu data yang diperoleh dari repsonden secara langsung oleh peneliti dengan cara memberikan kuesioner yang telah dipersiapkan sebelumnya dan data skunder yaitu data yang diperoleh dari instansi kesehatan (rumah sakit) seprti profil rumah sakit dan laporan Satuan Rumah Sakit Tentara Tk IV 01.07.04 Tahun 2016. Pengelolaan dan penyajian data yang dilakukan setelah data yang dikumpulkan yaitu dengan tahapan editing, coding, entry, cleaning.

Penelitian ini dilakukan dengan analisis univariat untuk mendeskripsikan karekteristik setiap variabel yang diteliti guna menghasilkan distribusi frekuensi dan persentase dari tiap variabel. Dan analisis bivariat dilakukan untuk mengetahui hubungan kedua variabel independen dan dependen. Untuk mengetahui adanya hubungan kedua variabel dilakukan dengan uji Chi Square dengan derajat kepercayaan $95 \% p=0,05$. Apabila $p$ value $<0,05$ maka Ho ditolak, artinya menunjukkan hubungan yang signifikan antara dua variabel dan apabila didapat $p$ value $>0,05$ maka Ho gagal ditolak, artinya tidak menujukkan adanya hubungan yang signifikan antara dua variabel.

\section{HASIL DAN PEMBAHASAN}

Hasil

Dari hasil analisis univariat diketahui bahwa pasien merasakan tidak puas atas pelayanan yang diberikan oleh rumah sakit yaitu sebanyak 48 orang $(55,2 \%)$, hal ini didukung oleh pernyataan tidak baik pada mutu pelayanan oleh responden pada kelima unsur pelayanan yang meliputi Reability (59,8\%). Assurance (59.8\%), Tangible $(60,9 \%)$, Emphaty $(67,8 \%)$, dan Responsiveness $(57,5 \%)$.

Dari hasil analisis hubungan mutu pelayanan dari reabity dengan kepuasan pasien, diperoleh bahwa ada sebanyak $36(69,2 \%)$ dari 52 pasien yang menyatakan tidak baik dalam kemampuan memberikan pelayanan (reability) dan merasakan tidak puas, dan hasil uji statistik diperoleh $\mathrm{p}$ value $=0,003(\mathrm{P}<0,05)$ dengan nilai POR (Prevalence Odds Ratio) $=4,313$.

Diketahui juga hubungan mutu pelayanan dari aspek assurance dengan kepuasan pasien, diperoleh bahwa ada sebanyak $34(65,4 \%)$ dari 52 pasien yang menyatakan petugas yang tidak baik dan merasakan tidak puas, hasil uji statistik diperoleh $\mathrm{p}$ value $=0,034(\mathrm{P}<0,05)$, dan nilai POR ( Prevalence Odds Ratio) $=2,833$. Diketahuinya hubungan mutu pelayanan dari bukti fisik (tangibles) dengan kepuasan pasien, diperoleh bahwa ada sebanyak $36(67,9 \%)$ dari 53 pasien yang menyatakan petugas tidak baik dan merasakan tidak puas, sedangkan hasil uji statistik diperoleh $\mathrm{p}$ value $=0,006(\mathrm{P}<0,05)$, dan nilai POR ( Prevalence Odds Ratio) $=3,882$. Diketahui hubungan mutu pelayanan dari aspek empati dengan kepuasan pasien, diperoleh bahwa ada sebanyak $38(64,4 \%)$ dari 59 pasien yang menyatakan petugas yang tidak baik dan merasakan tidak puas, hasil uji statistik diperoleh $\mathrm{p}$ value $=0,022(\mathrm{P}<0,05)$ dan nilai POR ( Prevalence Odds Ratio) $=3,257$. Diketahui hubungan mutu pelayanan antara responsiveness dengan kepuasan pasien, diperoleh bahwa ada 
sebanyak $35(70,0 \%)$ dari 50 pasien yang menyatakan tidak baik dan merasakan tidak puas, sedangkan dari hasil uji statistik diperoleh $\mathrm{p}$ value
$=0,003(\mathrm{P}<0,005)$ dan nilai POR $($ Prevalence

Odds Ratio) $=4,308$.

\section{Tabel 1}

Hubungan Reability dengan Kepuasan Pasien Rawat Inap di Rumah Sakit TentaraTK IV 01.07.04 Pekanbaru Tahun 2016

\begin{tabular}{ccccccccc}
\hline \multirow{2}{*}{ Reability } & \multicolumn{6}{c}{ Kepuasan Pasien } & \multirow{2}{*}{ P } & \multirow{2}{*}{ POR } \\
\cline { 2 - 6 } & \multicolumn{2}{c}{ Tidak Puas } & \multicolumn{2}{c}{ Puas } & \multicolumn{2}{c}{ Total } & Value & CI 95\% \\
\cline { 2 - 6 } & $\mathbf{n}$ & $\mathbf{\%}$ & $\mathbf{N}$ & $\mathbf{\%}$ & $\mathbf{n}$ & $\mathbf{\%}$ & & 4,313 \\
\hline Tidak Baik & 36 & 69,2 & 16 & 40,8 & 52 & 100 & & 0 \\
\hline Baik & 12 & 34,3 & 23 & 65,7 & 35 & 100 & & $(1,730-10,748)$ \\
\hline Sumber: Data Primer Penelitian & & & & & & & &
\end{tabular}

Tabel 2

Hubungan Assurance dengan Kepuasan Pasien Rawat Inap di Rumah Sakit Tentara TK IV 01.07.04 Pekanbaru Tahun 2016

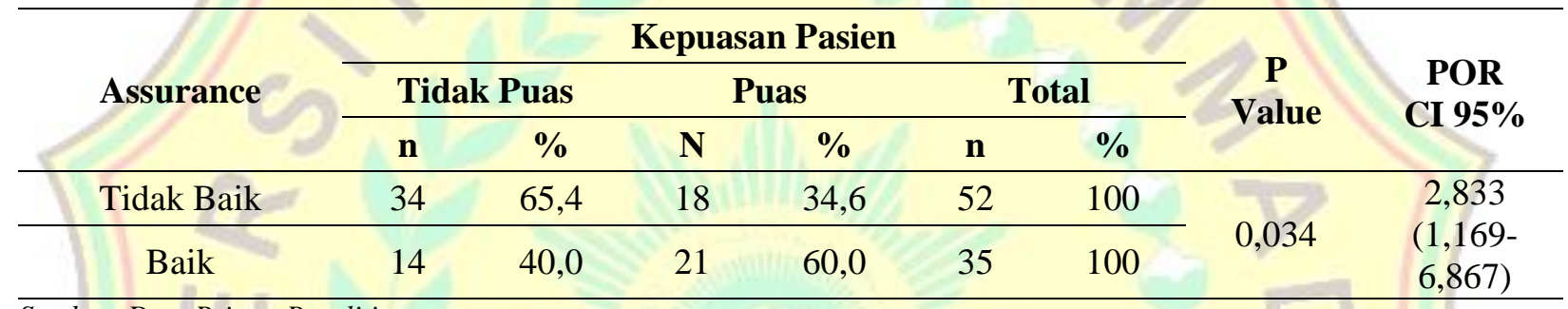

Sumber: Data Primer Penelitian

Tabel 3

Hubungan Tangibles dengan Kepuasan Pasien Rawat Inap di Rumah Sakit Tentara TK IV 01.07.04 Pekanbaru Tahun 2016

\begin{tabular}{|c|c|c|c|c|c|c|c|c|}
\hline \multirow{3}{*}{ Tangibles } & \multicolumn{6}{|c|}{ Kepuasan Pasien } & \multirow{3}{*}{$\begin{array}{c}\mathbf{P} \\
\text { Value }\end{array}$} & \multirow{3}{*}{$\begin{array}{c}\text { POR } \\
\text { CI 95\% }\end{array}$} \\
\hline & \multicolumn{2}{|c|}{ Tidak Puas } & \multicolumn{2}{|c|}{ Puas } & \multicolumn{2}{|c|}{ Total } & & \\
\hline & $\mathbf{n}$ & $\%$ & $\mathbf{N}$ & $\%$ & $\mathbf{n}$ & $\%$ & & \\
\hline Tidak Baik & 36 & 67,9 & 17 & 32,1 & 53 & 100 & \multirow{2}{*}{0,006} & \multirow{2}{*}{$\begin{array}{c}3,882 \\
1,563-9,641)\end{array}$} \\
\hline Baik & 12 & 35,3 & 22 & 64,7 & 34 & 100 & & \\
\hline
\end{tabular}

Sumber: Data Primer Penelitian

Tabel 4

Hubungan Emphaty dengan Kepuasan Pasien di Rumah Sakit Tentara TK IV 01.07.04 Pekanbaru Tahun 2016

\begin{tabular}{|c|c|c|c|c|c|c|c|c|}
\hline \multirow{3}{*}{ Emphaty } & \multicolumn{6}{|c|}{ Kepuasan Pasien } & \multirow{3}{*}{$\begin{array}{c}\mathbf{P} \\
\text { Value }\end{array}$} & \multirow{3}{*}{$\begin{array}{c}\text { POR } \\
\text { CI 95\% }\end{array}$} \\
\hline & \multicolumn{2}{|c|}{ Tidak Puas } & \multicolumn{2}{|c|}{ Puas } & \multicolumn{2}{|c|}{ Total } & & \\
\hline & $\mathbf{n}$ & $\%$ & $\mathbf{N}$ & $\%$ & $\mathbf{n}$ & $\%$ & & \\
\hline Tidak Baik & 38 & 64,4 & 21 & 35,6 & 59 & 100 & \multirow{2}{*}{0,022} & \multirow{2}{*}{$\begin{array}{c}3,257 \\
(1,274-8,329)\end{array}$} \\
\hline Baik & 10 & 35,7 & 18 & 64,3 & 28 & 100 & & \\
\hline
\end{tabular}

Sumber: Data Primer Penelitian 


\section{Tabel 5}

Hubungan Responsiveness dengan Kepuasan Pasien Rawat Inap di Rumah Sakit Tentara TK IV 01.07.04 Pekanbaru Tahun 2016

\begin{tabular}{|c|c|c|c|c|c|c|c|c|}
\hline \multirow{3}{*}{ Responsiveness } & \multicolumn{6}{|c|}{ Kepuasan Pasien } & \multirow{3}{*}{$\begin{array}{c}\mathbf{P} \\
\text { Value }\end{array}$} & \multirow{3}{*}{$\begin{array}{c}\text { POR } \\
\text { CI 95\% }\end{array}$} \\
\hline & \multicolumn{2}{|c|}{ Tidak Puas } & \multicolumn{2}{|c|}{ Puas } & \multicolumn{2}{|c|}{ Total } & & \\
\hline & $\mathbf{n}$ & $\%$ & $\mathbf{N}$ & $\%$ & n & $\%$ & & \\
\hline Tidak Baik & 35 & 70,0 & 15 & 30,0 & 50 & 100 & \multirow{2}{*}{0,003} & \multirow{2}{*}{$\begin{array}{c}4,308 \\
(1,740-10,662)\end{array}$} \\
\hline Baik & 13 & 35,1 & 24 & 64,9 & 37 & 100 & & \\
\hline
\end{tabular}

Pembahasan

a. Hubungan Reability dengan Kepuasan Pasien Rawat Inap Rumah Sakit Tentara Tk IV 01.07.04 Pekanbaru Tahun 2016

Hasil penelitian ini menunjukkan bahwa kemampuan petugas memberikan pelayanan (reability) yang tidak baik sebagian besar memberikan ketidakpuasan pasien yaitu sebanyak 36 orang $(69,2 \%)$. Hasil uji statistik menunjukkan bahwa $P$ value $0,003<0,05$, secara statistik disimpulkan bahwa terdapat hubungan yang signifikan antara reability dengan kepuasan pasien. Nilai PrevalenceOdd Ratio (POR) 4,313, artinya reability yang tidak baik berpeluang 4 kali memberikan ketidakpuasan pasien dibandingkan dengan reability yang baik.

Hasil penelitian ini didukung oleh penelitian yang dilakukan oleh Andreani (2014) menyatakan bahwa terdapat hubungan antara Reability (kehandalan) dengan mutu pelayanan terhadap kepuasan pasien.

\section{b. Hubungan Assurance dengan Kepuasan Pasien Rawat Inap Rumah Sakit Tentara Tk IV 01.07.04 Pekanbaru}

Hasil penelitian ini menunjukkan bahwa kemampuan dalam menanamkan kepercayaan pelanggan (assurance) yang tidak baik sebagian besar memberikan ketidakpuasan pasien yaitu sebanyak 34 orang $(65,4 \%)$. Hasil uji statistik menunjukkan bahwa $\mathrm{P}$ value $0,034<0,05$, secara statistik disimpulkan bahwa terdapat hubungan yang signifikan antara assurance dengan kepuasan pasien. Nilai Prevalence Odd Ratio (POR) 2,833, artinya assurance yang tidak baik berpeluang 2,8 kali memberikan ketidapuasan pasien dibandingkan dengan assurance yang baik.

Hasil penelitian ini didukung oleh penelitian yang dilakukan oleh Andreani (2014) menyatakan bahwa terdapat hubungan antara assurance (jaminan) dengan mutu pelayanan terhadap kepuasan pasien.

\section{c. Hubungan Tangibles dengan Kepuasan Pasien Rawat Inap Rumah Sakit Tentara Tk IV 01.07.04 Pekanbaru}

Hasil penelitian ini menunjukkan bahwa wujud kenyataan secara fisik (tangibles) yang tidak baik sebagian besar memberikan ketidakpuasan pasien yaitu sebanyak 36 orang (67,9\%). Hasil uji statistik menunjukkan bahwa $P$ value $0,006<0,05$, secara statistik disimpulkan bahwa terdapat hubungan yang signifikan antara tangibles dengan kepuasan pasien. Nilai Prevalence Odd Ratio (POR) 3,882, artinya tangibles yang tidak baik berpeluang 3,8 kali memberikan ketidapuasan pasien dibandingkan dengan tangibles yang baik.

Hasil penelitian ini didukung oleh penelitian yang dilakukan oleh Andreani (2014) menyatakan bahwa terdapat hubungan antara Tangibles (Tampilan fisik) dengan mutu pelayanan terhadap kepuasan pasien.

\section{d. Hubungan Emphaty dengan Kepuasan Pasien Rawat Inap Rumah Sakit Tentara Tk IV 01.07.04 Pekanbaru}

Hasil penelitian ini menunjukkan bahwa kemampuan memberikan perhatian (emphaty) yang tidak baik sebagian besar memberikan ketidakpuasan pasien yaitu sebanyak 38 orang $(64,4 \%)$. Hasil uji statistik menunjukkan bahwa 
$P$ value $0,022<0,05$, secara statistik disimpulkan bahwa terdapat hubungan yang signifikan antara emphaty dengan kepuasan pasien. Nilai PrevalenceOdd Ratio (POR) 3,257 artinya emphaty yang tidak baik berpeluang 3 kali memberikan ketidakpuasan pasien dibandingkan dengan emphaty yang baik..

Hasil penelitian ini didukung oleh penelitian yang dilakukan oleh Andreani (2014) menyatakan bahwa terdapat hubungan antara Emphaty (Empati) dengan mutu pelayanan terhadap kepuasan pasien.

\section{e. Hubungan Responsiveness dengan Kepuasan Pasien Rawat Inap Rumah Sakit Tentara Tk IV 01.07.04 Pekanbaru}

Hasil penelitian ini menunjukkan kemampuan memberikan tanggapan (responsiveness) yang tidak baik sebagian besar memberikan ketidak puasan pasien yaitu sebanyak 35 orang $(70,0 \%)$. Hasil uji statistik menunjukkan bahwa $P$ value $0,003<0,05$, secara statistik disimpulkan bahwa terdapat hubungan yang signifikan antara responsiveness dengan kepuasan pasien. Nilai Prevalence Odd Ratio (POR) 4,308 artinya responsiveness yang tidak baik berpeluang 4 kali memberikan ketidakpuasan pasien dibandingkan dengan responsiveness yang baik.

\section{KESIMPULAN DAN SARAN}

Kesimpulan

Terdapat hubungan antara reability, assurance, tangibles, emphaty dan responsiveness dengan kepuasan pasien terhadap mutu pelayanan di Ruang Rawat Inap Rumah Sakit Tentara Tk IV 01.07.04 Pekanbaru.

Saran

1. Disarankan kepada pihak rumah sakit agar memberikan pelatihan kepada petugas kesehatan agar dapat meningkatkan kemampuan dan pengetahuan untuk pengembangan program pengendalian mutu (quality assurence) dalam memberikan pelayanan prima yang diberikan pada masyarakat.
2. Perlunya menyakinkan kepada pasien bahwa mereka akan mendapatkan pelayanan yang baik sehingga menumbuhkan kepercayaan terhadap pasien.

3. Perlunya meningkatkan penampilan petugas serta lebih memperhatikan kebersihan ruangan.

4. Petugas kesehatan perlu menjalin komunikasi yang lebih baik kepada pasien sehingga petugas dapat mengetahui kesulitan yang dihadapi oleh pasien

5. Petugas kesehatan harus dapat cepat merespon kebutuhan pasien sehingga terpenuhinya kebutuhan kesehatan yang diharapkan oleh pasien.

\section{DAFTAR PUSTAKA}

Andreani, A. (2014). Faktor-Faktor Yang Berhubungan Dengan Mutu Pelayanan Terhadap Kepuasan Pasien.Skripsi. Program Studi Ilmu Kesehatan Masyarakat. STIKes Hang Tuah: Pekanbaru

Bustami. (2011). Penjaminan Mutu Pelayanan Kesehatan. Jakarta: Erlangga

Diah, W. (2009). Kepuasan Pasien Rawat Inap Terhadap Pelayanan Perawat.Tesis. Program Studi Magister Promosi Kesehatan. Universitas Diponegoro : Semarang

Herlambang, S. (2016). Manajemen Pelayanan Kesehatan Rumah Sakit.Yogyakarta: Gosyen Publishing

Kirom, B. (2015). Mengukur Kinerja Pelayanan dan Kepuasan Konsumen. Bandung: Pustaka Reka Cipta

Notoatmodjo, S. (2012). Metodologi Penelitian Kesehatan. Jakarta: Rineka Cipta

Novalia, E.(2014). Hubungan Mutu Pelayanan Pendaftaran Terhadap Kepuasan

Pasien Rawat Jalan.Skripsi . Program Studi Ilmu Kesehatan Masyarakat. STIKes Hang Tuah : Pekanbaru

Panduan Skripsi (2016). Program Studi Ilmu Kesehatan Masyarakat. STIKes Hang Tuah : Pekanbaru 
Purwoastuti, E. (2015). Mutu Pelayanan Kesehatan dan Kebidanan. Yogyakarta: Pustaka Baru Press

Rumah Sakit Tentara. (2015). Profil Rumah Sakit Tentara Tk IV 01.07.04 Tahun 2015. Pekanbaru

Rusli, R. (2015). Faktor-faktor yang Berhubungan dengan Kepuasan Pasien di Ruang Rawat Inap.Skripsi. Program Studi Ilmu Kesehatan Masyarakat. STIKes Hang Tuah : Pekanbaru

Peraturan Menteri Kesehatan Republik Indonesia Nomor 147 Tentang Rumah Sakit

Setyobudi, I. (2014). Konsumen dan Pelayanan Prima. Yogyakarta: Gava Media

Sudian, T. (2012). Hubungan Kepuasan Pasien
Terhadap Mutu Pelayanan Kesehatan di RS Cut Mutia. http://www.google.jurnal.theses.jiptum m.org/, diakses pada tanggal 17 Maret 2016

Undang-Undang Republik Indonesia Nomor 36 Tahun 2009 Tentang Kesehatan

Undang-Undang Republik Indonesia Nomor 44 Tahun 2009 Tentang Rumah Sakit

Wawan, A. (2011). Teori dan Pengukuran Pengetahuan, Sikap dan Perilaku Manusia. Yogyakarta: Nuha Medika

Wenny, B. (2015). Survei Kepuasan Pasien Pada Rawat Inap. Jurnal Pasien Rawat Inap Vol. 5 No. 11 hal 38 Surakarta. 